\title{
Conceptual Challenges for Advancing the Socio-Technical Underpinnings of Health Informatics
}

\author{
Sue Whetton ${ }^{*}, 1$ and Andrew Georgiou ${ }^{2}$ \\ ${ }^{1}$ University Department of Rural Health, Tasmania, Locked Bag 1372, Launceston, Australia \\ ${ }^{2}$ Health Informatics Research \& Evaluation Unit, Faculty of Health Sciences, The University of Sydney, Australia
}

\begin{abstract}
This discussion paper considers the adoption of socio-technical perspectives and their theoretical and practical influence within the discipline of health informatics. The paper highlights the paucity of discussion of the philosophy, theory and concepts of socio-technical perspectives within health informatics. Instead of a solid theoretical base from which to describe, study and understand human-information technology interactions we continue to have fragmented, unelaborated understandings. This has resulted in a continuing focus on technical system performance and increasingly managerial outputs to the detriment of social and technical systems analysis. It has also limited critical analyses and the adaptation of socio-technical approaches beyond the immediate environment to the broader social systems of contemporary society, an expansion which is increasingly mandated in today's complex health environment.
\end{abstract}

Keywords: Complex systems, evaluation studies, medical informatics, sociotechnical, theory.

\section{INTRODUCTION}

Socio-technical perspectives focus on understanding the interaction between two interrelated systems, the technical system and the social system, within a particular environmental context. It is a complex field where many disciplines apply their theoretical and methodological focus to explore the organisational, professional, cultural and technical issues inherent in the design of health care information systems. Multi-disciplinary input has generated a rich diversity of understandings about socio-technical systems and the way they operate. This has in turn facilitated flexibility in identifying the issues and generating the solutions for health information systems design challenges. It also ensures the relevance of socio-technical design to the many different and constantly evolving environments and professions in health care. To fully exploit the potential of socio-technical perspectives, academics and professionals need to engage in a critical dialogue to identify, discuss, and question different perspectives and understandings. This enables the integration of insights and achievements into a more cohesive socio-technical underpinning of health informatics. This discussion paper contributes to the dialogue. It begins with a brief overview of the focus and objectives of the pioneers of socio-technical design. An understanding of the views of these pioneers is fundamental to effective implementation of socio-technical perspectives. The discussion then turns to current applications of sociotechnical perspectives in contemporary health informatics research, teaching and practice. The discussion highlights perspectives that encourage broader debate and critical analysis of the interpretation and application of sociotechnical perspectives in health informatics.

*Address correspondence to this author at the University Department of Rural Health, Tasmania, Locked Bag 1372, Launceston, Australia; Tel: + 61 6324 4025; Fax: + 616324 4040; E-mail: Sue.Whetton@utas.edu.au

\section{SOCIO-TECHNICAL PERSPECTIVES: BEGINNINGS}

Although this discussion is not a historical review of socio-technical perspectives it is important to highlight the values and principles which shaped the work of the early pioneers and guided their desire to maintain a balance between the social and technical systems in contemporary practice. Socio-technical perspectives have been applied to the design of workplace technology since the mid-twentieth century. Originating in the social sciences, they were first advocated by psychologists at the Tavistock Institute of Human Relations (London) in the 1950s. The perspectives were promoted to counter the perceived de-humanising effect of scientific management practices that were being adopted in workplaces throughout twentieth century industrial society [1]. The early work was underpinned by humanistic values and a primary goal of socio-technical design was to improve the quality of working life and job satisfaction of employees [1-3]. This focus on workers was the impetus for conceptualising a socio-technical system as two separate but interconnected systems, a social system and a technical system. The term socio-technical was used to emphasise that both systems are equally important, and that employees are complementary to technology, not subordinate to it. Optimisation of the overall system therefore required excellence in technical performance and quality in people's work lives. Socio-technical systems were represented as open systems evolving through interaction with the environment in which they were embedded. This resulted in an emphasis on ethnographic studies and action research [1, 4]. Early researchers emphasised the links between research, theory and practice - "There should be no theory without practice, no practice without research. Sociotechnical designers have always tried to test and develop theory" [1] (p. 321).

Over time socio-technical perspectives were adapted by disciplines in both the physical and social sciences, resulting 
in today's complex multi-disciplinary field which incorporates a range of theoretical and methodological perspectives [1, 4]. Several studies have explored this complexity. Land identified two conflicting standpoints - the first emphasises humanistic principles, while the second reflects managerial ideals where socio-technical principles are viewed as instruments for achieving the primary objectives of the organisation [5]. Morris highlighted four different perspectives - the technology/engineer, the social scientist, the complex systems engineer and the organisational scientist, each of which draw on particular aspects of socio-technical design [4]. These and similar studies suggest that that there is no such thing as "the" sociotechnical approach but that different research traditions offer complementary, and sometimes contradictory, approaches [6]. As different perspectives, each underpinned by different values and ideas developed, the original humanistic values, which were the impetus for our socio-technical pioneers lost their prominence $[4,5]$. When health informatics academics and professionals began to focus their attention on sociotechnical perspectives in the late $1990 \mathrm{~s}$, they were confronted by a complex, multi-disciplinary field.

\section{SOCIO-TECHNICAL PERSPECTIVES IN HEALTH INFORMATICS}

The application of socio-technical perspectives to health informatics was advocated as a means for understanding and mitigating the poor uptake and performance of information systems within health care [7-9]. In 1994 Sittig identified the grand challenge of health informatics as being to identify techniques to ease incorporation of information management into the infrastructure of organisations [10]. This was echoed by Atkinson et al. in 2001, who argued for a socio-technical research and development agenda to "undertake participative, multi-stakeholder problem solving within a healthcare context" (p 1). In 2004 Coiera suggested that "if health care is to evolve at a pace that will meet the needs of society it will need to embrace this science of socio-technical design" [7] (p. 1197).

Evaluations of failed systems emphasised the importance of understanding the complex cultural and organisational aspects of the health care environment and the way these interacted with the technical system. Socio-technical design was identified as an approach that acknowledged this interaction while also accounting for the complexities of the healthcare environment $[7,11,12]$. The approach generated interest and the term "socio-technical" appeared in definitions of health informatics and in the titles of text books, journal articles, and conference papers. The literature began to discuss the importance of cultural and organisational issues.

These developments heralded a shift away from the technocentric preoccupation with "what is needed to make the technical system work right" toward an increasing interest in social and organisational issues. This is demonstrated by the diversity of the topics addressed in the literature. These include a focus on work practices [13], teamwork issues and communication [14-15] user attitudes, perceptions, reactions, and satisfaction [16-19], stakeholder consultation [20] and usability [21]. Emerging sociotechnical orientations also influenced research practice with qualitative or mixed methods beginning to be used alongside traditional quantitative-based approaches. Socio-technical perspectives fostered the view that particular methodologies and techniques are more appropriate for some functions than others and that a combination of approaches provides a more comprehensive outcome [22].

While there has been a significant growth in the appreciation and adoption of socio-technical perspectives in health informatics, the dominant focus continues to be on the performance of the technology system as the primary objective. Although the social system is acknowledged as important, it is discussed in the context of minimising resistance to the technological system and problems are formulated in terms of understanding and minimising this resistance [4]. This is indicated in both the methods adopted for research and the language used to report outcomes of that research. In their inventory of studies of information technology in healthcare, Ammenwerth and de Keizer found only $5 \%$ used qualitative methods, $12 \%$ used combinations of quantitative and qualitative methods, while $83 \%$ focused on quantitative methods [23]. Westbrook et al. found that "few studies incorporate a multi-disciplinary approach or use a multi-method design" [24] (p. 1324).

While the technocentric term of "user" [12] may be less evident in the literature today, many reports construct the issues in terms of changing clinical work flows, managing staff resistance and ensuring compliance to maximise system performance. Discussions of education and professional skills also indicate that technology remains a primary focus. In a review of recommendations and guidelines for core skills and knowledge for health informatics professionals, Whetton noted "an emphasis on skills and knowledge pertaining to health informatics/health information systems, computer science and decision support domains, with far fewer core skills drawn from sociological, psychological or management domains (the socio in the socio-technical)" (p223) [8]. This suggests that a social science orientation has yet to gain a strong presence in socio-technical analyses within health informatics. Nor is the potential of the social science perspective well understood. As Coiera notes, "much of the growing STS literature in health informatics is focussed at the phenomenological level" seeking to "explain what people do when they are using technology" [25] (p. 6). While this is certainly one focus, and one which would undoubtedly have the support of the Tavistock pioneers, the social sciences are much more complex, studying both structural and interactionist aspects of human society and human behaviour and utilising different methods as appropriate.

One final observation to be made concerns the scope of socio-technical perspectives as they are applied in health informatics. Discussions in the literature predominantly focus on the practical application of socio-technical analyses. Few elucidate, analyse or critique the underlying principles, concepts or theoretical perspectives adopted in the work. Westbrook et al. noted that many studies of reasons for health IT system failure are retrospective designs that are "limited in their ability to hypothesise about causal factors" [24] (p. 1125). Rather than a solid theoretical base from which to describe, study and understand human-information technology interactions, we have fragmented, unelaborated 
understandings. This has resulted in a continuing focus on technical system performance often as a substitution for social and technical system analysis. This has limited critical analyses and consigned socio-technical approaches to address the immediate health care setting without attention to the broader environment of the contemporary society.

\section{BROADENING THE FOCUS}

The need to broaden the scope of socio-technical perspectives has been acknowledged for some time. Just as health informatics professionals were becoming interested in the approach, Lamb et al. were arguing that "it is becoming increasingly apparent that there is a need for fresh conceptualizations of socio-technical arrangements" [26] (Page 1614). The development of more complex, interconnected information systems raised questions about the ongoing relevance and utility of socio-technical approaches. Critics suggested that increasingly networked organisations were creating fluid boundaries between systems and their environments. They were also resulting in increasing interaction between information systems and the wider environment. These trends were making it increasingly difficult to determine the boundaries of local systems [1, 4, 27, 28]. Today, a socio-technical system such as an electronic health records system embedded in the department of a hospital will be impacted by other departments and sections in that hospital $[29,30]$. It will also be affected by the external environment, which may include the health organisation, funding bodies and government regulators. This logically extends to the society within which the hospital is located and, in today's increasingly interconnected world, to the global environment. Thus, socio-technical systems at the local level will be influenced by broader economic, political and cultural systems and vice versa. As Brown and Vergragt observe, "it has become increasingly clear that human-IT micro systems are themselves embedded within larger systemic contexts, and that both these contexts, as well as the interactions and change processes both between and among them, need to be clearly conceptualized and explored in greater detail" [31] (Page 127).

Socio-technical approaches within the wider academic information systems research community have begun to explore the interaction between the information system and the broader social environment $[1,4,27,28]$. Now may be the time to broaden the focus in health informatics. Social science perspectives provide the means for focussing attention on the social system as both separate from and connected to the technical system. This was a fundamental principle of the early socio-technical perspectives which is often overlooked in the contemporary literature.

\section{CONCLUSION}

The importance of a strong research base to underpin theory and practice is acknowledged to some extent in the health informatics literature $[7,31]$. However, the association between socio-technical concepts and health informatics practice and research is rarely articulated. Similarly, the elucidation of the theories, concepts and principles that underlie socio-technical perspectives, or their particular application to the health informatics domain, are still limited. As a consequence, rather than a solid theoretical base from which to describe, study and understand humaninformation technology interactions we have fragmented, unelaborated understandings about socio-technical perspectives. This is resulting in a continuing focus on the performance of the technical system and limited attention to the social system. Elucidation of the concepts, theories and values of socio-technical perspectives needs to occur in both education and research literature. The absence of this debate is limiting the ability of health informatics academics and professionals to fully explore and apply socio-technical approaches in the increasingly complex environments of contemporary health care.

\section{REFERENCES}

[1] Mumford E. The story of socio-technical design: reflections on its successes, failures and potential. Inform Syst J 2006; 16(4): 317.

[2] Scacchi W. Socio-technical design. The Encyclopedia of HumanComputer Interaction Berkshire Publishing Group, 2004: pp. 656-9.

[3] Majchrzak A, Borys B. Generating testable socio-technical systems theory. J Eng Technol Manage 2001; 18(3-4): 219-40.

[4] Morris A. Socio-Technical Systems in ICT: A Comprehensive Survey. Technical Report DISI-09-054. Ingegneria e Scienza dell'Informazione, University of Trento 2009.

[5] Land F. Evaluation in a socio-technical context. In: Basskerville R, Stage J, De Gross J, Eds. Organizational and social perspectives in information technology. Boston, USA: Klumer Academic Publications 2000.

[6] Aarts J, Gorman P. IT in health care: sociotechnical approaches "To err is system". Int J Med Inform 2007; 76(Suppl 1): 1-3.

[7] Coiera E. Four rules for the reinvention of health care. BMJ 2004; 328(7449): 1197-9.

[8] Whetton S. Health Informatics - a socio-technical perspective. Melbourne: Oxford University Press 2005.

[9] Berg M. Patient care information systems and health care work: a sociotechnical approach. Int J Med Inform 1999; 55(2): 87-101.

[10] Sittig DF. Grand challenges in medical informatics? J Am Med Inform Assoc 1994; 1(5): 412-3.

[11] Altman R. Informatics in the care of patients: ten notable challenges. West J Med 1997; 166(2): 118.

[12] Atkinson C, Eldabi T, Paul R, Pouloudi A. Investigating integrated socio-technical approaches to health informatics. Published by the IEEE Computer Society: Citeseer 2001.

[13] Balka E, Whitehouse S. Whose work practice? Situating an electronic triage system within a complex system. Stud Health Technol Inform 2007; 130: 59.

[14] Clemensen J, Larsen S, Kirkevold M, Ejskjaer N. Telemedical teamwork between home and hospital: a synergetic triangle emerges. Stud Health Technol Inform 2007; 130: 81.

[15] Creswick N, Westbrook J. Social networks of staff in an emergency department, in HIC2008 Conference Proceedings. Melbourne: Health Informatics Society of Australia 2008.

[16] Knight J, Patrickson M, Gurd B. Understanding GP attitudes towards a data amalgamating health informatics system. eJHI 2008; 3(2): e12.

[17] Gururajan R, Hafeez-Baig A, Kerr D. Reactions and perceptions of healthcare professional towards wireless devices in healthcare environment in the developing world: a case of Pakistan. eJHI 2008; 3(2): 10 .

[18] Bichel-Findlay J, Callen J, Sara A. An information system's contribution to work satisfaction: differing perspectives between doctors and nurses, in HIC2008 Conference Proceedings. Melbourne: Health Informatics Society of Australia 2008.

[19] Parle A, Lassere M. Engaging the clinician: the value of rapid prototyping of 'lightweight' electronic health records. In: HIC2008 Conference proceedings. Melbourne: Health Informatics Society of Australia 2008.

[20] Balbo S, Gogler J, Steinkrug J, Lee L, Scheidt S, Hullin C. The importance of including users in clinical software evaluation: what usability can offer in home monitoring, in HIC 2008 Conference Proceedings. Melbourne, Australia: Health Informatics Society of Australia 2008. 
[21] Kjeldskov J, Skov M, Stage J. A longitudinal study of usability in health care: Does time heal? Int J Med Inform 2010; 79(6): e13543.

[22] Ackroyd S. Methodology for management and organisation studies; some implications of critical realism. In: Fleetwood S, Ackroyd S, Eds. In critical realist applications - organisation and manage-ment studies. London: Routledge 2004; pp. 137-63.

[23] Ammenwerth E, de Keizer N. An inventory of evaluation studies of information technology in health care trends in evaluation research 1982-2002. Methods Inform Med 2005; 44(1): 44-56.

[24] Westbrook JI, Braithwaite J, Iedema R, Coiera EW. Evaluating the impact of information communication technologies on complex organizational systems: a multi-disciplinary, multi-method framework. Stud Health Tech Inform 2004; 107(2): 1323-7.

[25] Coiera E. Putting the technical back into socio-technical systems research. Int J Med Inform 2007; 76 (Suppl 1): S98-103.

[26] Lamb R, Sawyer S, Kling R. A social informatics perspective on socio-technical networks. in Proceedings of the 32nd Annual
Hawaii International Conference on Systems Sciences. Hawaii, USA 2000.

[27] Wood-Harper T, Wood B. Multiview as social informatics in action: past, present and future. Inform Technol People 2005; 18(1): 26-32.

[28] Cartelli A. Socio-technical theory and knowledge construction Towards new teaching paradigms. J Issues Inform Sci Inform Technol 2007; 4: 1-14.

[29] Georgiou A, Westbrook JI, Braithwaite J, et al. When requests become orders - A formative investigation into the impact of a Computerized Physician Order Entry system on a pathology laboratory service. Int J Med Inform 2007; 76(8): 583-91.

[30] Georgiou A, Westbrook J, Braithwaite J, Iedema R. Multiple perspectives on the impact of electronic ordering on hospital organisational and communication processes. HIM J 2005; 34(4): 130-4.

[31] Brown H, Vergragt P. Bounded socio-technical experiments as agents of systemic change: the case of a zero-energy residential building. Technol Forecast Soc 2008; 75(1): 107-30.

(C) Whetton and Georgiou; Licensee Bentham Open.

This is an open access article licensed under the terms of the Creative Commons Attribution Non-Commercial License (http://creativecommons.org/licenses/by-nc /3.0/) which permits unrestricted, non-commercial use, distribution and reproduction in any medium, provided the work is properly cited. 